\title{
Your precious engineers will be increasingly disabled by a shortage of optics technicians. What can be done?
}

\section{Alexis Vogt}

Alexis Vogt, "Your precious engineers will be increasingly disabled by a shortage of optics technicians. What can be done?," Proc. SPIE 11143, Fifteenth Conference on Education and Training in Optics and Photonics: ETOP 2019, 111431 (3 July 2019); doi: 10.1117/12.2523596 Photonics: ETOP 2019, 2019, Quebec City, Quebec, Canada 
Invited Paper

\title{
Your precious engineers will be increasingly disabled by a shortage of optics technicians. What can be done? \\ Alexis Vogt \\ Monroe Community College, 1000 E. Henrietta Road, Rochester, NY, 14623
}

\begin{abstract}
The global optics, photonics, and imaging industry is growing, but a worldwide shortage of optics technicians exists. Engineers are being called upon to do the work of optics technicians. This paper describes how Monroe Community College, the United States' only community college awarding associate degrees in precision optics, is educating diverse optics and photonics technicians.
\end{abstract}

Keywords: Optics technicians, precision optics, training, community college, apprenticeships

\section{INTRODUCTION}

Optics technicians manufacture optics, perform testing and evaluation of optics components and systems, and work with scientists and engineers in research, design, development, manufacturing, and quality control. Optics technicians are critical to companies, but the technical workforce for the optics industry is shrinking at an alarming rate.

Every day the shortage of optics technicians is impacting optics companies nationwide. In daily morning meetings across the country, the scarcity of technicians is ever present. Picture the scenario: at an optics company's daily morning meeting to discuss new orders within the last 24 hours and key shipments required to go out, someone hesitantly points out that the lead technician has called in sick. The lead technician has a two-year degree in optics and has arguably become one of the most important people in the company. The technician is relied upon for nearly every single shipment that leaves the company. Without the technician, the key shipment will not go. The company does not have anyone to backfill the absent technician's job or skillset. What does the optics company do if something happens to the technician or when the technician decides to retire? This scenario is playing out in optics companies around the world. The absence of a single technician can delay shipments, stifle innovation, and impede growth.

\section{UNITED STATES DEMAND FOR OPTICS TECHNICIANS}

In 1971, Monroe Community College (MCC), located in Rochester, New York, was the first school in the nation to create a two-year degree program for training technicians to work in the optics industry. Today, MCC remains the nation's only community college awarding associate degrees in precision optics. In 2019, 12 MCC graduates entered the optics industry to fill an annual demand of 574 technicians in the Finger Lakes area ${ }^{1}$. This leaves $98 \%$ of Upstate New York skilled optics technician job openings unfilled. Coupled with industry reports that $20 \%$ of experienced technicians and engineers are approaching retirement ${ }^{2}$, the need for skilled optics technicians is vast. And the demand for precision optics technicians is far greater when the worldwide optics industry is taken into account.

As the September 2018 Interagency Task Force in Fulfillment of Executive Order 13806 report "Assessing and Strengthening the Manufacturing and Defense Industrial Base and Supply Chain Resiliency of the United States" found, the United States industrial base faces an unprecedented set of challenges due in part to a loss of vital skills in the domestic workforce. "Declines in manufacturing employment... have created key vulnerabilities and weaknesses that potentially threaten the nation's defense-related manufacturing capabilities." This loss has impacted the optics manufacturing industry directly and led to gaps in skilled labor. The report concluded, "decreased emphasis on domestic manufacturing threatens technical innovation and thereby America's ability to capture emerging technologies. A reduced domestic manufacturing footprint reduces incentives and the ability of companies to invest in new capabilities and process improvements, further deteriorating industrial base capabilities critical to maintaining a global advantage." 3 


\section{OPTICS COMPANY RESPONSES TO SHORTAGE OF TECHNICIANS}

The shortage of skilled optics technicians forces optics companies to hire employees without optics experience and then provide optics training internally. Optimax Systems Inc. (Ontario, NY) is not able to find enough skilled optics technicians to fill their growing workforce so they widely advertise they are looking to hire artists, musicians, gamers, chefs, and automobile mechanics - people with demonstrated strong hand-eye coordination. Optimax then invests in their internal training program to properly teach their new employees the precision optics trade.

Corning Inc. (Fairport, NY) launched a Technician Pipeline Program to try to help fill their shortage of optics technicians. The program includes a two-year scholarship to earn an associates of applied science (AAS) degree in Optical Systems Technology at Monroe Community College, job placement during the program, a full-time salary while in the program, and conversion to a full time technician role at Corning Incorporate upon completion of the program.

\section{APPRENTICESHIP MODEL}

Because skilled optics and photonics technicians are so scarce, some optics companies are creating their own apprenticeship training programs. According to the United States Department of Labor, advanced manufacturing companies are increasingly turning to apprenticeship to develop, grow, and retain a skilled workforce. Apprenticeship programs combine structured on-the-job learning with related instruction in technical areas to produce qualified, highlyproductive employees for careers requiring precision skills. Apprenticeship training ensures workers have the knowledge and competencies companies need for today and tomorrow.

New York State has the only established Precision Optics Manufacturing Technician Apprenticeship. The registered apprenticeship requires 6,000 hours of on-the-job experience and 144 hours per year of related instruction. Four years ago, Optimax Systems Inc. (Ontario, NY) created the first Precision Optics Manufacturing Technician Apprenticeship. Enrolled apprentices spend a month working in different manufacturing areas across the company and take Optical Systems Technology courses at Monroe Community College to fulfill related instruction requirements. Other optics companies, including JML Optical (Rochester, NY) and OptiPro Systems (Ontario, NY) also established optics apprenticeship programs.

The American Precision Optics Manufacturers Association (APOMA), the working group of the top United States optics manufacturers, is collaborating closely with its member companies to roll out the Precision Optics Manufacturing Technician Apprenticeship nationwide. APOMA is committed to promoting and advancing opportunities for the precision optics industry, and one of those key areas is developing a skilled optics workforce. With a nationwide Precision Optics Manufacturing Technician Apprenticeship, more highly skilled optics technicians will enter the workforce and assuage the shortage currently stifling the industry.

\section{WORLDWIDE DEMAND FOR OPTICS TECHNICIANS}

Skilled optics technicians are needed not only in the United States, but around the world. In a survey among 1,700 small and medium-sized German companies, about three quarters report that the shortage of skilled workers impairs their innovation activities ${ }^{4}$. A lack of optics technicians impedes the productivity of an optics company that is forced to hire engineers to fill technician openings. The shortage of technicians is stifling innovation and requiring engineers with advanced degrees to complete the work of technicians. Development of the current and next-generation optics manufacturing workforce is vital to the future success of the optics industry.

In the last 12 months, 73 companies and five staffing agencies from around the world contacted Monroe Community College seeking to hire students from its Optical Systems Technology program. As the only community college in the nation graduating precision optics technicians, Monroe Community College is not producing enough skilled optics technicians to meet the demand. 


\section{STRENGTHENING THE OPTICS TECHNICIAN TRAINING PROGRAM}

To strengthen the optics and photonics workforce and provide students with employment opportunities in regional industries to fill high skill, high demand positions, Monroe Community College was awarded a National Science Foundation Advanced Technological Education grant. Monroe Community College's Optics \& Photonics Technology INnovation-OPT IN! program, launched in April 2017, has goals of strengthening the MCC Optical Systems Technology program and academic pipeline and broadening industry and community partnerships.

To strengthen the MCC Optical Systems Technology program and academic pipeline, curriculum was developed, high school dual enrollment opportunities were created, articulation agreements with four-year universities were established, and faculty professional development was initiated. MCC partners with high schools to strengthen the optics academic pipeline and meet the needs of the optics industry. Dual enrollment courses are college courses taught in high schools, by qualified high school teachers. MCC faculty provide professional development for high school teachers for preparation to teach precision optics dual enrollment courses. Through the support of the National Science Foundation grant, MCC pioneered an optics dual enrollment model where a high school science teacher teaches the MCC Introduction to Optics college course in their high school, to their high school students. The Introduction to Optics dual enrollment course is currently taught in 11 high schools in the Rochester, N.Y. region. High school students who successfully complete dual enrollment courses receive transferable college credit. By completing Introduction to Optics as a dual enrollment course, students advance into the optics career ladder and start college with advanced standing.

The Optical Systems Technology program at MCC offers a two-year associates of applied science (AAS) degree in traditional optics, an AAS degree in electro-optics, a one-year certificate in optics manufacturing, and a $2+2$ degree option. Electro-optics is synonymous with photonics, but the MCC OST program was created before the word photonics was invented. The $2+2$ option is a dual degree program offered by Monroe Community College and select four-year institutions. Each 2+2 degree program enables students to take advantage of unique benefits: concurrent applications to both institutions, one application fee, recommended course selections, and guaranteed acceptance to the four-year college upon completion of the associate degree and all $2+2$ requirements. Currently, MCC partners with the Rochester Institute of Technology's (RIT) Imaging Science BS degree and the University of Rochester's Institute of Optics for 2+2 transfer options. Students enrolled in the MCC Optical Systems Technology program have options of going to work or taking advantage of the $2+2$ transfer to continue on for a four-year degree.

Successful training of optics technicians is not possible without support of the optics industry. Through the second goal of the $O P T I N$ ! program, industry and community partnerships are broadened through expansion of experiential learning opportunities and development of marketing and outreach initiatives to strengthen the optics and photonics workforce. Strong industry partnerships provide students access to experiential learning through authentic and highly relevant work experiences within industry. This on-the-job training is invaluable. To best prepare students to enter the fast paced, high skilled optics and photonics industry, internship opportunities have been created for MCC optics students. For students to become familiar with the optics industry, companies open their doors to provide tours. Tours of optics companies are valuable for MCC optics students as well as high school dual enrollment students, teachers, and guidance counselors, prospective students, and families.

Through expanding industry and community partnerships, the entire region works together to promote and encourage the study of optics and photonics, an industry vital to our economy. Strong community partnerships provide K-12 students an awareness of education and in-demand career options in optics and photonics. Of particular importance, is an effort to increase the enrollment of underrepresented populations in the career pathways that are available in optics and photonics. Recruitment and outreach activities targeted toward historically underrepresented populations including women, veterans, African Americans, Latinos, and low income help broaden awareness of optics and photonics technology and employment opportunities.

By increasing awareness of optics and photonics through presentations to high school students and guidance counselors, more students recognize the opportunities to join an exciting, growing field and upon completion of the MCC optics program will help fill the technician-level workforce gap that currently exists. Awareness of optics and photonics extends a mindfulness of MCC's optics program to the understanding of what optics and photonics companies in the region manufacture. 
MCC program development and improvement provide students with an optics and photonics career pipeline from precollegiate to baccalaureate with the skills and competencies gained through enhanced curriculum and reinforced by internships and job readiness activities.

\section{CONCLUSION}

The optics industry's shortage of skilled technicians is a national security issue. There are not enough precision optics training programs in the world; MCC alone cannot produce the workers to sustain the industry. Other trades, including welding, plumbing, and metal machining, for example, have trade schools. The optics industry does not. For the optics industry to continue to thrive and grow, a collaborative approach is needed to replicate the Monroe Community College Optical Systems Technology program.

*avogt4@monroecc.edu; $\quad$ phone $\quad 1 \quad 585 \quad$ 292-2685; $\quad$ monroecc.edu

